\title{
Hands Free 3.c Technique - Step by Step Maximizes the Duration of Sublingual Microcirculatory Image - A Prognosis to Monitor Microcirculation in Patients with Covid-19 and Sepsis
}

\author{
Técnica Manos Libres 3.c - Paso a Paso: Maximiza la Duración de la Imagen Microcirculatoria \\ Sublingual - Un Pronóstico para Monitorear la Microcirculación en Pacientes con Covid-19 y Sepsis
}

\author{
José Custódio Feres Vieira
}

\begin{abstract}
VIEIRA, J. C. F. Hands free 3.c technique - step by step: maximizes the duration of sublingual microcirculatory image - a prognosis to monitor microcirculation in patients with covid-19 and sepsis. Int. J. Odontostomat., 15(3):741-747, 2021.

ABSTRACT: The sublingual area is the most used site to assess microcirculation in critically ill patients at bedside. The prerequisite for microcirculation evaluation, using HVM imaging (Handheld Vital Microscopy), is to ensure measurements free of image artifacts, confirming an adequate analysis of blood flow. However, this would only be possible with standardizati on in the process of image capture. Currently, with the Hands On technique, the recommended capture time is 4 to 20 seconds, which is already considered laborious. In this study, the Hands Free 3.C technique proposes an alternative that maximizes the image period of sublingual microcirculation (as suggested by the Second Consensus) for more than 12 minutes, and thus opening the way for future research aiming at therapeutic maneuvers in critically ill patients such as COVID -19 and sepsis.
\end{abstract}

KEY WORDS: sublingual microcirculation, HVM imaging, Hands Free 3.C technique, stabilizer, duration of sublingual image, Covid -19 , sepsis.

\section{INTRODUCTION}

Blood microcirculation is responsible for transporting oxygen from red blood cells in capillaries to parenchyma cells. (Bateman et al., 2003). Studied in the pathophysiology of sepsis, heart failure, and hypovolemia (Donati et al., 2013). Today, understanding Covid-19's pathophysiology also depends on the interpretation of its impact on the vascular system, particularly on the microcirculatory system (Grewal et al., 2021).

In the presence of severe disease, the change in microcirculation precedes the change in macrocirculation (Trzeciak \& Rivers 2005); thus, it seems sensible to monitor this organ and, if necessary, improve its function (Elbers \& Ince, 2006).

To study the microcirculation, the Incident DarkField Illumination method (Sherman et al., 1971) was used. The OPS (Orthogonal Polarization Spectral) was the first HVM (Handheld Vital Microscopy), and allowed a direct view of the microcirculation (Groner et al., 1999). Other generations of HVM came next such as: SDF, Sidestream Dark Field (Goedhart et al., 2007) and CytoCam (Aykut et al., 2015).

The sublingual area is the most used place to assess microcirculation in critically ill patients at bedside (Ince et al., 2018). The prerequisite for the evaluation of microcirculation, using HVM imaging, is to ensure measurements free of image artifacts, confirming an adequate analysis of blood flow (Massey \& Shapiro, 2016); but that would only be possible with the standardization of image capture.

In the usual technique (Hands On), the operator holds the HVM with his hands and touches its tip to the tissue in order to observe the microcirculation (Fig. 1A). The captured area is only $1 \mathrm{~mm} 2$, but it is projected 
VIEIRA, J. C. F. Hands free 3.c technique - step by step: maximizes the duration of sublingual microcirculatory image - a prognosis to monitor microcirculation in patients with covid19 and sepsis. Int. J. Odontostomat., 15(3):741-747, 2021.

on the computer screen with a magnification of more than 300 times. However, a small movement of the operator's hand can cause the video to shift on the computer screen (Massey \& Shapiro).

Currently, the recommended capture time is 4 to 20 seconds, which is already considered laborious (Ince et al.), as it is evident that the duration and stability of the video go together (Elteren et al., 2015). In this way, it is unlikely that the operator will be able to capture a stable image of the microcirculation for a longer period by holding the HVM in his hands without generating image artifacts.

In a European Society for Critical Care Medicine task force, recently published in the Second Consensus on the assessment of sublingual microcirculation in critically ill patients, statements were made on the need to acquire and interpret images captured from the sublingual microcirculation. In the part of future perspectives of this same consensus (Ince et al.), two sentences justified this study: "35. Tools should be developed to make pressure-artifact-free measurements and allow single-spot measurements to be made during a therapeutic " 37 . Technology should be developed to allow stable measurements to be made for longer periods of time to allow continuous measurement during, for example, a therapeutic maneuver allowing observation of the response of single vessels before and after the intervention"

Thus, a recent study specifically evaluated the stability of a HVM replica, using Hands Free 3.C technique (Vieira, 2021). The results obtained were statistically significant when compared to Hands On (usual) versus Hands Free techniques (Fig. 1). The stability time of HVM using the 3.C support increased from 4 seconds to 300 seconds (Vieira).

In this scenario, offering health professionals the possibility of extending the capture duration of sublingual microcirculatory image from seconds to minutes seems to be a relevant and innovative path. Objective: to capture images of sublingual microcirculation for a longer period than usual, using Hands Free 3.C technique

\section{MATERIAL AND METHOD}

The Hands Free 3.C technique was used in healthy and awake volunteer as a support tool for HVM (Figs. 2 and $3 \mathrm{~A}$ ).

Comparative drawings between the two techniques: Hands On figure on the left and Hands Free figure on the right, representing the operator at different times in capturing videos of sublingual microcirculation (Fig. 1)

Sequence of facial arch adjustments 3.C on the mannequin:

Some adjustments are necessary for the use of facial arch 3.C, before capturing the images in the volunteer (Fig. 3B):
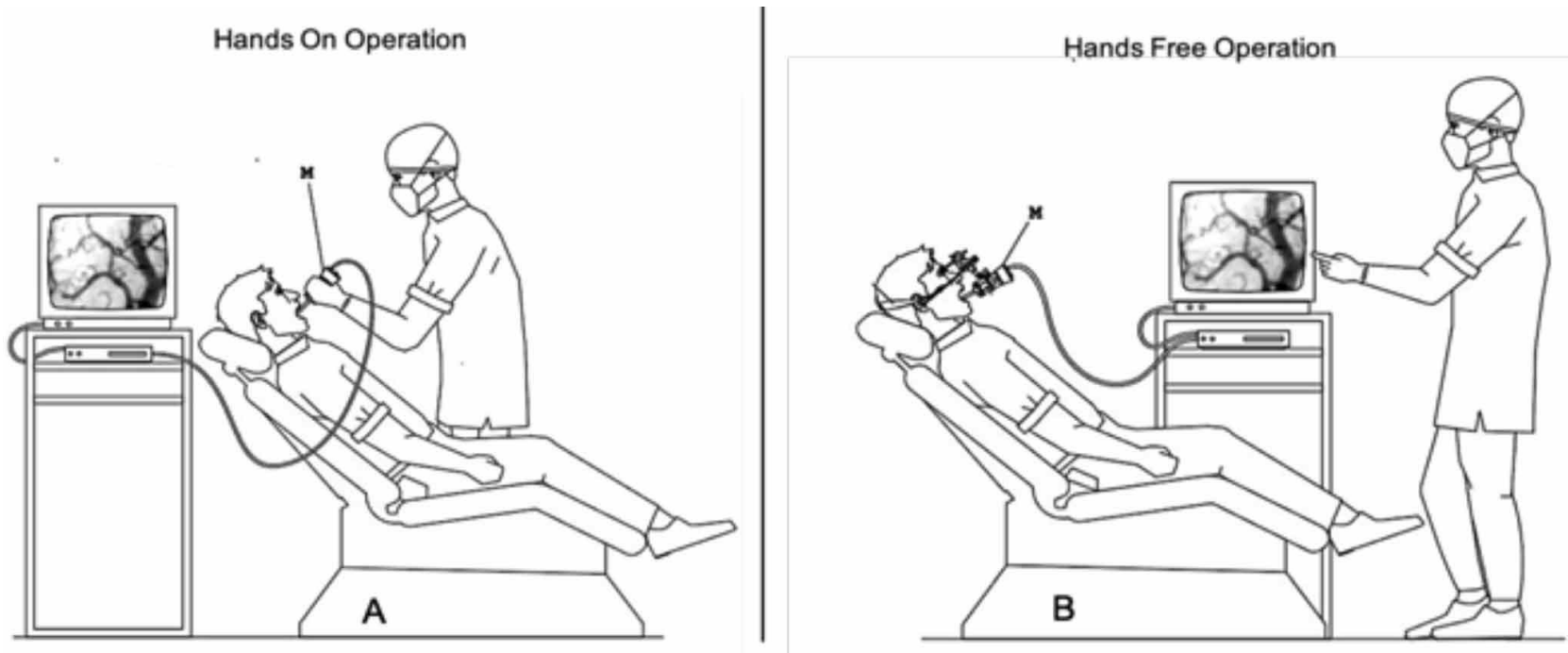

Fig. 1. A. Usual technique on Hands On. B. Innovative Hands Free technique 3.C. 
Adjustment of facial arch size (S, M, L) and adjustment of the ear support simultaneously (Fig. 2A).

- Adjustments of nasal support and stabilization brace on the dorsal part of the user's head (Fig. 3B).

As soon as the operator attaches the HVM to adjustable rubber straps, (figure $2 \mathrm{~B}$ ), he will be able to capture microcirculatory images in the sublingual area (Fig. 3B).

-When choosing the most representative area of the microcirculation, the operator must activate the lock of the articulated arm (Fig. 2B) and, thus, put into practice the Hands Free 3.C technique (Fig. 3B).
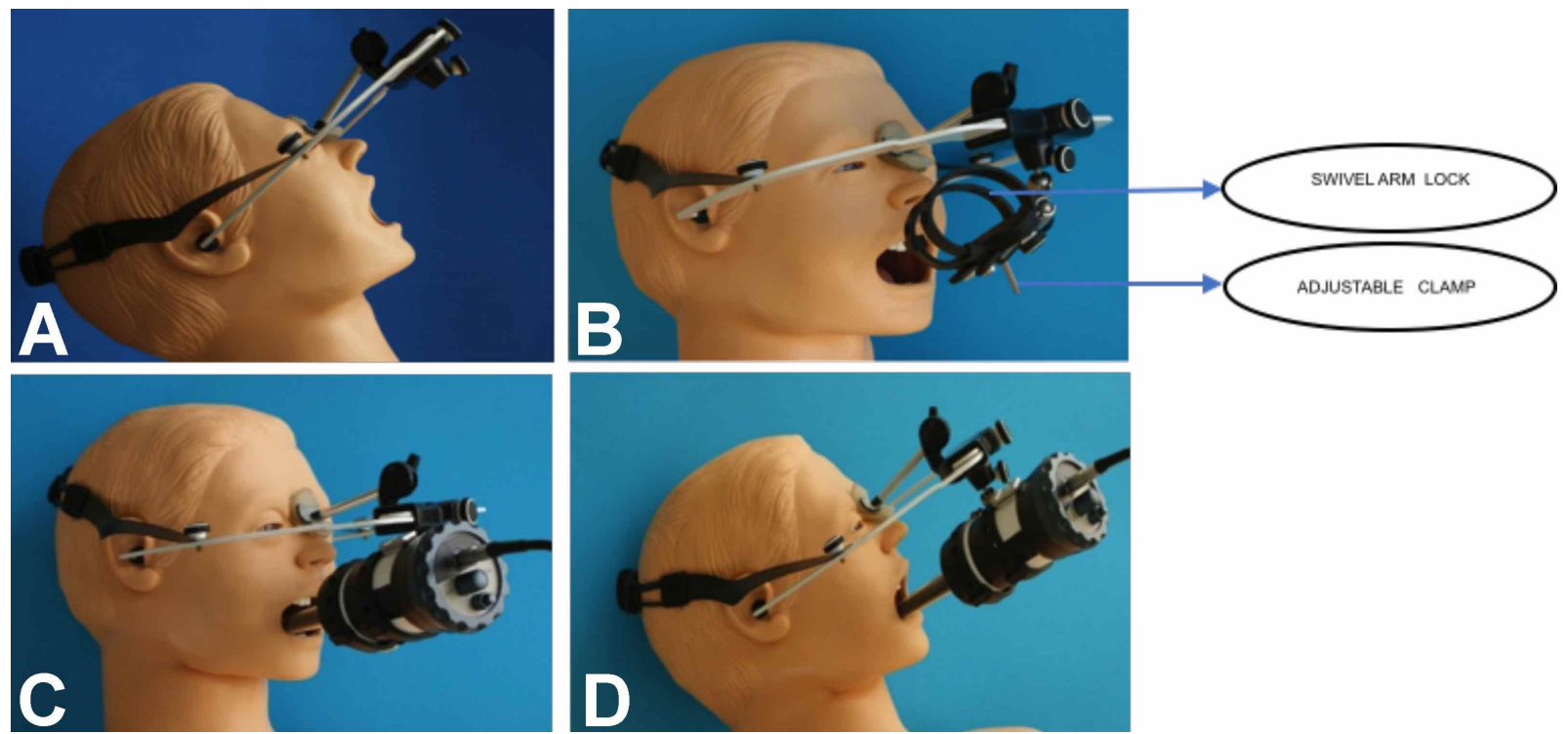

Fig. 2. Facial arch 3.C (A) partially assembled on the mannequin. (B) Universal clamp and swivel arm lock adjusted - blue arrow. Assembly of facial arch 3.C with HVM already attached to the clamp (C, D).
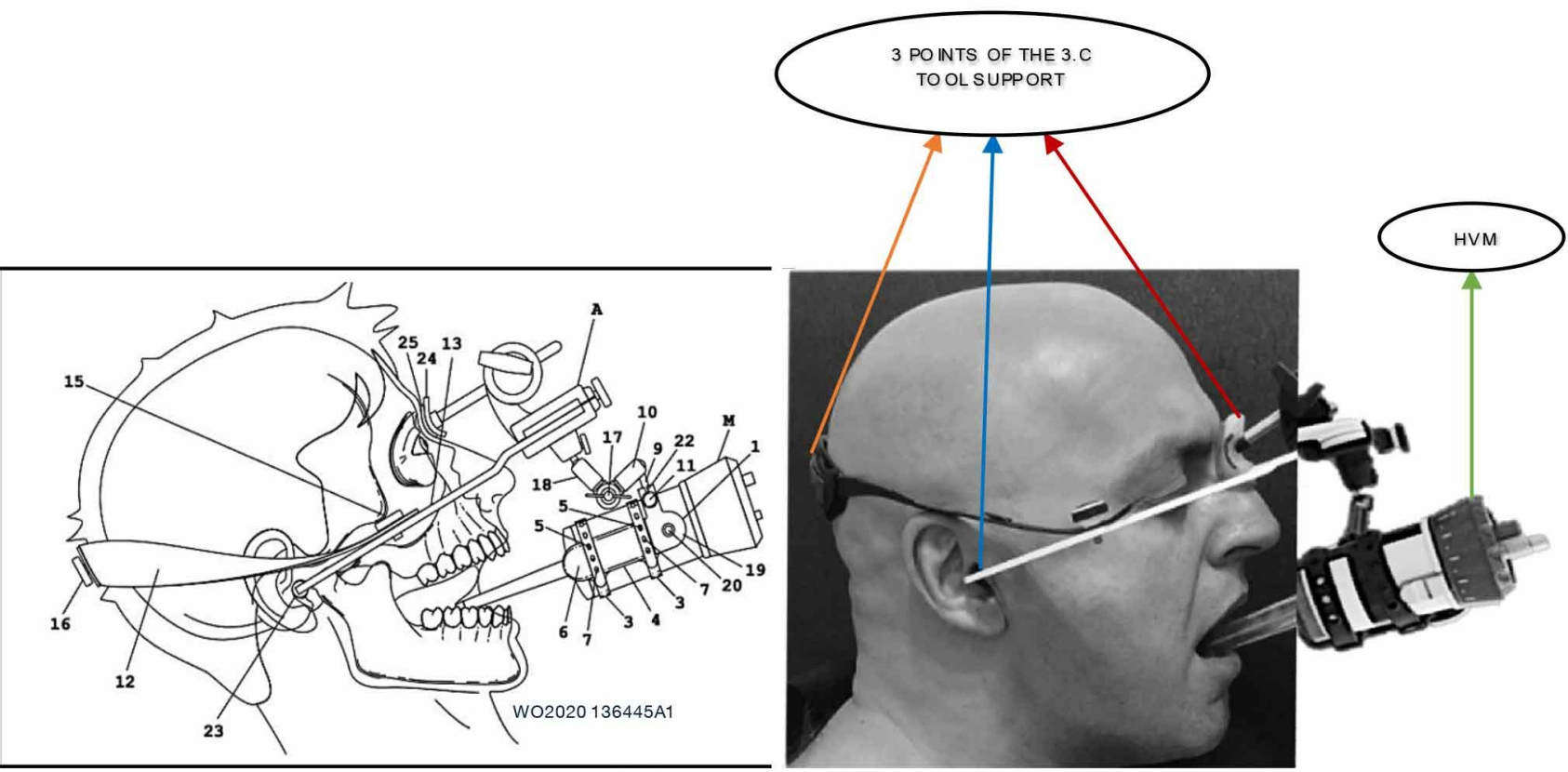

Fig. 3. A. Drawing of facial arch 3.C. B. The accessory in use with Hands Free 3.C technique, 3 points of support: orange arrow - dorsal head support, blue arrow - ear support, red arrow - nasal support, for HVM stabilization (green arrow) in the sublingual area. 
VIEIRA, J. C. F. Hands free 3.c technique - step by step: maximizes the duration of sublingual microcirculatory image - a prognosis to monitor microcirculation in patients with covid19 and sepsis. Int. J. Odontostomat., 15(3):741-747, 2021.

\section{RESULTS}

The HVM (Handheld Vital Microscopy) captured images of sublingual microcirculation with a longer duration, and also explored areas such as the sublingual caruncle and its excretory physiological activity in relation to salivary flow. The use of HVM, with the aid of Hands Free technique, and 3.C support, offered this possibility.

In Figure 4, the green lights indicated that in the brightness, focus and stability category, the film is within the parameters. Video over 40 seconds long. The AVA 4.2 software was used.

\section{Timeline, video 4:}

. 46 ", the video is stable and longer than usual. 46 ", end of video

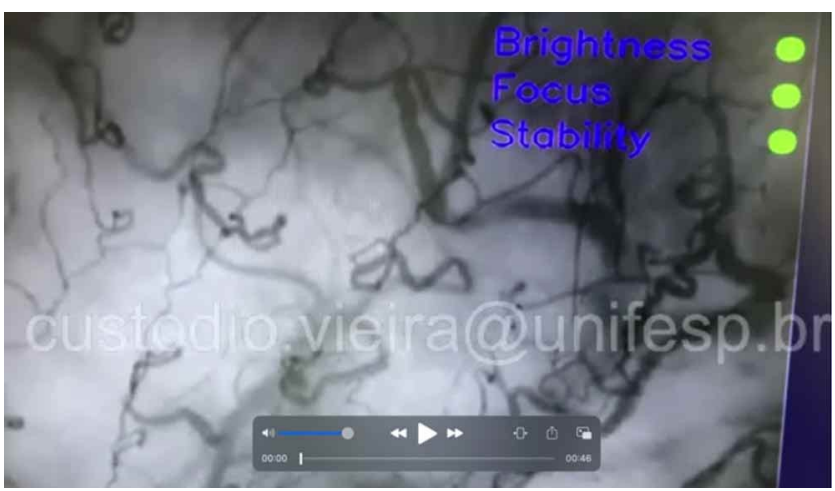

Fig. 4. Image of sublingual microcirculation using Hands Free 3.C technique. Follow the video link in figure 4 :

https://1drv.ms/u/s!An2hayTIUZDrhJpyb5eNS9a8MtjJkA?e=usth8d

In Figure 5, image of sublingual microcirculation recorded over 300 seconds in duration with AVA 3.2 software

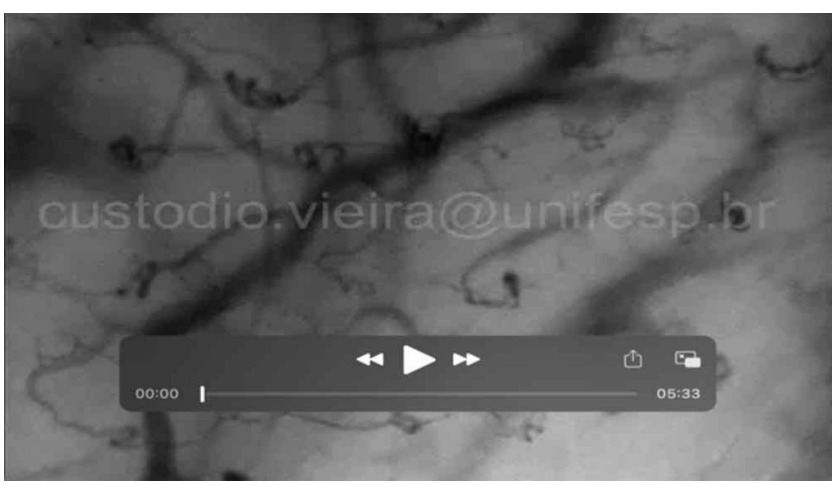

Fig. 5. Image of sublingual microcirculation using Hands Free 3.C technique. Follow the video link in figure 5 : https://1drv.ms/v/s!An2hayTIUZDrhJpwU0SOtUu8JH15_Q?e=Ofjjfl

\section{Timeline, video 5 :}

Zero - 5'33", Hands Free 3.C technique with image of sublingual microcirculation of vessels with continuous flow.

\section{- 5’33 "end of video}

Image of sublingual microcirculation recorded over 12 minutes (Fig. 6). Note the effect that the tip of HVM has on the tissue, regarding the microcirculatory flow.

\section{Timeline, video 6:}

\section{- Zero - 48 ", apparently continuous microcirculation flow}

. 50 "- 1'28", image displacement and apparent microcirculation with continuous flow

. 1'30 "- 5'12", displacement of volunteer's tongue causing pressure on the tip of HVM and generating an image of slow or paralyzed microcirculatory flow - 5'13 - 6 ', from the moment the volunteer's tongue starts to relax, it retracts, thus promoting a decrease in tissue pressure on HVM

- 8'20" - 9', suggests an image with slow or paralyzed microcirculatory flow, caused by the pressure of sublingual tissue exerted on the tip of HVM

. 9'3"-11", video with continuous microcirculatory flow without apparent presence of tissue pressure on the tip of HVM

-11'- small displacement of tongue causing some variation in the microcirculation flow

- 11'-12'30", microcirculation flow apparently continuous and without variation

\section{. 12'30", end of video}

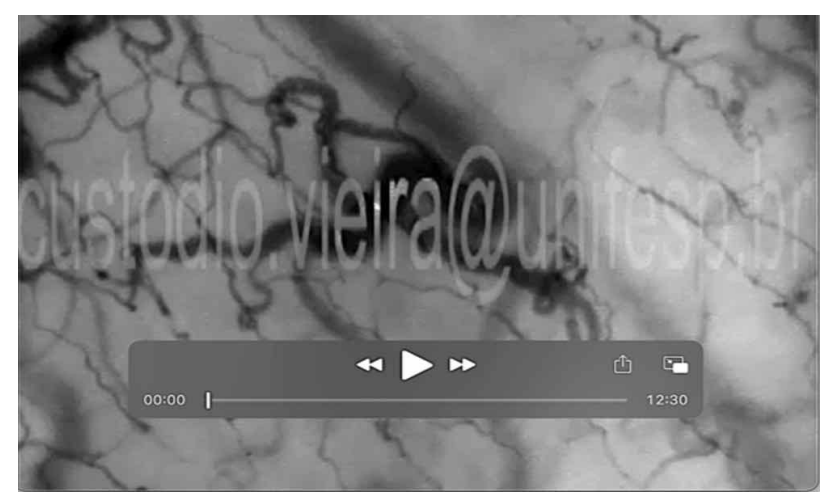

Fig. 6. Image of sublingual microcirculation using Hands Free 3.C technique. Follow the video link in figure 6 :

https://1drv.ms/v/s!An2hayTIUZDrhJpxg2gWpGIrsgVoEA?e=D224IT

During the exploration of sublingual area with Hands Free 3.C technique, the sublingual caruncles 
stood out for their anatomy and physiological importance in salivary excretion. The largest excretory duct of the sublingual gland, called Bartholin's sublingual duct, joins Wharton's duct, near the sublingual caruncle. The sublingual caruncle is a papiIla located medial to sublingual gland and lateral to lingual frenulum, with the function of excreting saliva (Armstrong et al., 2013).

In Figure 7 , the microcirculation around the sublingual caruncle is evident, notice the salivary flow being expelled during the video, video lasting 5'33"

Timeline, video 7:

- Zero to 4'14 "- microcirculation with apparently continuous flow in vicinity of the caruncle

- 4'14"-visible elements come out through the caruncle showing the salivary flow

- 4'30"- in displacement of caruncle image, the microciculation becomes more evident and with an apparently continuous flow

- 4'30 "- 5'33' '- apparent continuous flow of microcirculation

-5'33 "- end of vídeo

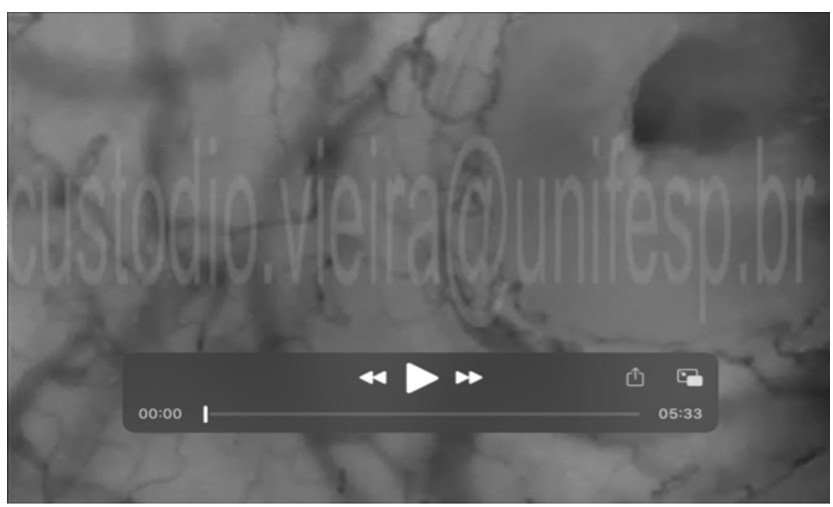

Fig. 7. Hands Free technique 3.C, image of microcirculation around the sublingual caruncle. Follow the video link in figure 7:

https://1drv.ms/u/s!An2hayTIUZDrhJp1pnoq2W5yIT_Dww?e=48fjsG

Figure 8. represents the sublingual caruncle with the surrounding microcirculation. Note during the video the exact moment of the caruncle opening

Timeline, video 8:

3 "- moment of caruncle opening

. 5 "- end of video

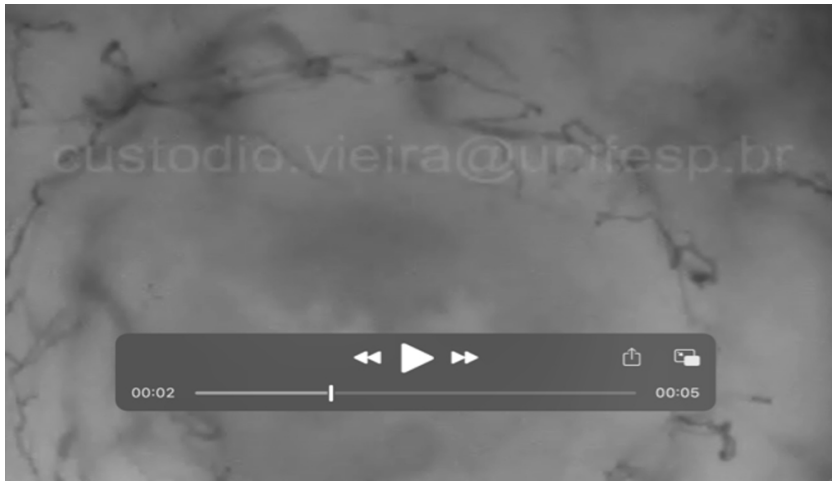

Fig. 8. Image of microcirculation around the sublingual caruncle, with Hands Free technique 3.C Follow the video link in figure 8 :

https://1drv.ms/v/s!An2hayTIUZDrhJpv26FSOWHrn93N6w?e=ZLEf08

Hands Free Technique 3.C - positive points:

1. Enables the attachment of different HVMs, as the rubber straps are adjustable (Fig. 2B).

2. Ensures stability of the whole set after adjusting the arch opening (S, M, L), the ear support, the nasal support and the dorsal head band (Fig. 3B).

3. Allows the operator to choose the best sublingual area, thanks to articulated arms with lock (Fig. 3B).

4. Extends the duration of images in the video from seconds to minutes (Figs. 5 to 7 ).

5. Allows the operator to watch the microcirculatory flow live, with the hands free, after choosing the ideal sublingual microcirculatory area and locking the articulated arm of the facial arch 3.C (Fig. 1B).

6. Facilitates the different areas study of oral cavity, such as the caruncle and its relationship with saliva (Figs. 7 and 8).

7. It should reduce the learning period for experienced operators and beginners.

Hands Free Technique 3.C - negative points:

1- The support tool 3.C could be lighter, despite the aluminum structure

2- The ear support (Fig. 3B), should be more comfortable

3- The support device 3.C must be adjusted sparingly to find the ideal position, avoiding creating discomfort for the user. 
VIEIRA, J. C. F. Hands free 3.c technique - step by step: maximizes the duration of sublingual microcirculatory image - a prognosis to monitor microcirculation in patients with covid19 and sepsis. Int. J. Odontostomat., 15(3):741-747, 2021.

\section{DISCUSSION}

Microcirculation has been studied in the sepsis pathophysiology, heart failure and hypovolemia (Donati et al., 2013). The understanding of Covid-19's pathophysiology, however, depends on the interpretation of its impact on the vascular system, particularly on the microcirculatory system (Grewal et al.).

The method chosen to study microcirculation was Incident Dark-Field Illumination (Sherman et al.). The HVM (Handheld Vital Microscopy) enabled the clinical introduction of new microcirculatory imaging techniques (Groner et al.), such as direct observation of microcirculation at bedside (Goedhart et al.; Aykut et al.). The sublingual area is the most used site to assess microcirculation in critically ill patients (Ince et al.).

The prerequisite for evaluating microcirculation using imaging is to ensure that measurements are free of image artifacts (Massey \& Shapiro). In the usual technique (Hands On), the acceptable duration of the video, without moving the image of microcirculation, is 4 to 20 seconds, which is already considered laborious (Ince et al.), because the duration and stability video images go together (Elteren et al.).

A task force from European Society for Critical Care Medicine published the Second Consensus on the assessment of sublingual microcirculation in critically ill patients (Ince et al.) (Table 9) in future perspectives, suggesting:

"35. Tools should be developed to make pressureartifact-free measurements and allow single-spot measurements to be made during a therapeutic maneuver".

"37. Technology should be developed to allow stable measurements to be made for longer periods of time to allow continuous measurement during, for example, a therapeutic maneuver allowing observation of the response of single vessels before and after the intervention".

This scientific challenge stimulated the development of a tool to assist health professionals that reduces the image artifacts of sublingual microcirculation generated by usual technique (Vieira).

The 3.C tool was developed from the facial arch used in dentistry. To stabilize it on the head, there are 3 points of support: nasal, auricular, and dorsal of the head (Fig. 3B). To attach HVM to the arch, an adjustable rubber clamp does this job. This rubber band makes the 3.C facial arch universal, as it is regulated according to the available HVM (Fig. 2B).

A recently published study reports the increase from 4 to 300 seconds, with the application of Hands Free technique with 3.C support, using a replica of HVM. However, without obtaining images of sublingual microcirculation (Vieira).

Now, with an original HVM, and not a replica, this study captured healthy images of sublingual microcirculation, allowing the operator a longer duration of recording time of sublingual microcirculation with HVM.

In Figure 4, the AVA 4.2 software, specific for microcirculation, was used. This software has a device with green or red lights, which are located at the top right of the computer screen. When the red lights turn green, it means that the image will be within acceptable parameters. The image quality categories that the software provides to assist the operator are: brightness, focus and stability (Fig. 4).

In the video represented by Figure 4, the green light remains constant in brightness and stability category; but, in the focus category, green and red light alternate, having the volunteer's respiratory movement as probable cause, since HVM appears to be static with the use of Hands Free 3.C technique.

In Figures 4 to 7 , the non-movement of HVM tip guarantees a stable image for a longer period. In Figure 6, the use of Hands Free 3.C technique increased the period of sublingual microcirculatory image capture to another 700 seconds in relation to the recommended one, which is from 4 to 20 seconds. Yet, the stabilization and the time taken to capture the image depend, in addition to HVM, on the volunteer's in vigil cooperation.

A small pressure of the tongue on the tip of HVM (Fig. 6) fixed in the ideal position, at 1'30", distorts the flow of microcirculation, being able to generate pressure artifacts and consequent unreliable data. However, from the moment the volunteer's tongue starts to relax, it retracts, promoting a decrease in tissue pressure on HVM and, thus, the microcirculatory flow is continuous again.

In Figures 4, 5 and 7, with the volunteer's cooperation, the videos show the continuous flow of microcirculation, and without theinterference of the 
tongue movements as the video remains stable in the same sublingual area.

Anatomical curiosities captured by HVM: The sublingual caruncle is a papilla located medial to the sublingual gland and lateral to the lingual frenulum with the function of excreting saliva (Armstrong et al.).

The sublingual caruncle and its excretory physiological activity in relation to salivary flow (Figs. 7 and 8) were observed. Videoswith unpublished images, thanks to Incident Dark-Field Illumination method and HVM by Hands free 3.C technique were performed.

In the video represented by Figure 7, at 4 '15', images of unexpected elements appear, expelled by sublingual caruncle showing the salivary flow. It was an unprecedented and remarkable scene.

Therefore, information about microcirculatory perfusion would be of great interest in intensive care to predict results and potentially guide therapy. Thus, this is the first work to produce images with microcirculation duration for longer periods, paving the way for future studies to be carried out with critically ill patients such as COVID -19 and sepsis

CONCLUSION. In this study, the Hands Free 3.C technique proposes a new alternative that maximizes the imaging period of sublingual microcirculation, an open path for future research aimed at therapeutic maneuvers in critically ill patients such as COVID -19 and sepsis. It is a hypothesis to be confirmed with further studies.

VIEIRA, J. C. F. Técnica manos libres 3.c - paso a paso: maximiza la duración de la imagen microcirculatoria sublingual - un pronóstico para monitorear la microcirculación en pacientes con covid y sepsis. Int. J. Odontostomat.,15(3):741-747, 2021.

RESUMEN: El área sublingual es el sitio más utilizado para evaluar la microcirculación junto a la cama en pacientes críticamente enfermos. El requisito previo para la evaluación de la microcirculación, utilizando imágenes HVM (Microscopía Vital Portátil), es asegurar mediciones libres de artefactos de imagen, confirmando un análisis adecuado del flujo sanguíneo. Sin embargo, esto solo sería posible con la estandarización en el proceso de captura de imágenes. Actualmente, con la técnica Hands On, el tiempo de captura recomendado es de 4 a 20 segundos, lo que ya se considera laborioso. En este estudio, la técnica Hands Free 3.C propone una alternativa que maximiza el período de imagen de la microcirculación sublingual (como sugiere el Segundo Consenso) durante más de 12 minutos, y abre así el camino a futuras investigaciones encaminadas a maniobras terapéuticas en pacientes con enfermedades graves como COVID -19 y sepsis.

PALABRAS CLAVE: microcirculación sublingual, imágenes HVM, técnica manos libres 3.C, estabilizador, duración de la imagen sublingual, COVID -19, sepsis.

\section{REFERENCES}

Armstrong, M. A. \& Turturro, M. A. Salivary gland emergencies. Emerg. Med. Clin. North Am., 31(2):481-99, 2013.

Aykut, G.; Veenstra, G.; Scorcella, C.; Ince, C. \& Boerma, C. CytocamIDF (incident dark field illumination) imaging for bedside monitoring of the microcirculation. Intensive Care. Med. Exp., 3(1):40, 2015.

Bateman, R. M.; Sharpe, M. D. \& Ellis, C. G. Bench-to-bedside review: microvascular dysfunction in sepsis--hemodynamics, oxygen transport, and nitric oxide. Crit. Care, 7(5):359-73, 2003.

Elbers, P. W. \& Ince, C. Mechanisms of critical illness--classifying microcirculatory flow abnormalities in distributive shock. Crit. Care, 10(4):221, 2006

Elteren, H. A.; Ince, C.; Tibboel, D.; Reiss, I. K. \& de Jonge, R. C. J. Cutaneous microcirculation in preterm neonates:comparison between sidestream dark field (SDF) and incident dark field (IDF) imaging. J. Clin. Monit. Comput., 29(5):543-8, 2015.

Goedhart, P. T.; Khalilzada, M.; Bezemer, R.; Merza, J. \& Ince, C. Sidestream Dark Field (SDF) imaging:a novel stroboscopic LED ring-based imaging modality for clinical assessment of the microcirculation. Opt. Express, 15(23):15101-14, 2007.

Grewal, S.; Harjo, B.; Aykut, G.; Ergin, B.; Nowitzky, R.; Ince, C. \& Akin, S. Case report: sublingual microcirculatory alterations in a covid-19 patient with subcutaneous emphysema, venous thrombosis, and pneumomediastinum. Front. Med. (Lausanne), 7:624695, 2021.

Groner, W.; Winkelman, J. W.; Harris, A. G.; Ince, C.; Bouma, G. J.; Messmer, K. \& Nadeau, R. G. Orthogonal polarization spectral imaging: a new method for study of the microcirculation. Nat. Med., 5(10):1209-12, 1999.

Ince, C.; Boerma, E. C.; Cecconi, M.; De Backer, D.; Shapiro, N. I.; Duranteau, J.; Pinsky, M. R.; Artigas, A.; Teboul, J. L.; Reiss, I. K. $\mathrm{M}$; et al. Second consensus on the assessment of sublingual microcirculation in critically ill patients: results from a task force of the European Society of Intensive Care Medicine. Intensive Care Med., 44(3):281-99, 2018.

Massey, M. J. \& Shapiro, N. I. A guide to human in vivo microcirculatory flow image analysis. Crit. Care, 20:35, 2016.

Sherman, H.; Klausner, S. \& Cook, W. A. Incident dark-field illumination:a new method for microcirculatory study. Angiology, 22(5):295-303, 1971.

Vieira, J. C. F. Hands free technique: new tool possibility for image capture of sublingual microcirculation with handheld vital microspopy - HVM. Int. J. Odontostomat., 15(1):181-8, 2021.

Corresponding author:

José Custódio Feres Vieira

Programa de Pós Graduação

PPG Ciência Cirúrgica Interdisciplinar

Universidade Federal de São Paulo (Unifesp)

São Paulo - BRAZIL

E-mail: custodio.vieira@unifesp.br 